\title{
Sobre portas, paredes e afetos: casa, territorialidade e identidade entre os segmentos populares
}

\author{
On doors, walls and affections: \\ home, territoriality and identity among the popular sectors
}

\author{
Rosemere Santos Maia \\ rosemaia@terra.com.br \\ Universidade Federal do Rio de Janeiro
}

\begin{abstract}
Resumo: O presente artigo aborda a casa dos segmentos populares nas suas múltiplas dimensões - objetiva/subjetiva/intersubjetiva - demonstrando como suas velhas e novas funções revelam-se por intermédio das territorialidades que emergem em seu contexto. Detendo um valor inestimável para os seus moradores, a casa comunica a identidade de quem a habita; promete abrigo, segurança, privacidade, liberdade e intimidade; estabelece um "corte" com o "mundo exterior", deixando-o em suspenso, ao mesmo tempo em que se afirma enquanto um "pedaço" para os que se intitulam seus "donos"; pode ser tanto "vitrine" - espaço que distingue uns de outros, pelas das cores, formas e bens que exibe, como pode transmutar-se em local de labuta, espaço de trabalho incansável. Casa - viva, única, relacional - é lócus de contradições.
\end{abstract}

Palavras-chave: Casa. Territorialidade. Identidade. Cidade. Pobreza urbana.

\begin{abstract}
This article discusses the house of the popular segments in its many dimensions - objective/subjective/intersubjective - demonstrating how their old and new features are revealed through the territorialities that arise in their context. Holding inestimable value for residents, house communicates the identity of the person who inhabits it; it promises shelter, security, privacy, freedom and intimacy; it establishes a "cut" with the "outside world", leaving residents suspended, at the same time that they are stated as a "piece" for those who call themselves their "owners", it can be both "window" - space that differs one from another, through colors, shapes and goods displayed, as can transmute itself into place of labor, space of tireless work. The living-house - unique, relational - is the locus of contradictions.
\end{abstract}

Keywords: Home. Territoriality. Identity. City. Urban poverty.

Resumen: Este artículo aborda la casa de los segmentos populares en sus múltiples dimensiones - objetiva/subjetiva/intersubjetiva - demostrando cómo sus viejas y nuevas funciones se revelan a través de la territorialidad emergen en su contexto. Deteniendo un valor incalculable para sus residentes, la casa comunica a la identidad de la persona que la habita: promete vivienda, la seguridad, la privacidad, la libertad y la intimidad, establece un "corte" con el "mundo exterior", dejándolo suspendido, al mismo tiempo en que se declara como un "pedazo" para aquellos que se llaman sus "dueños", puede ser tanto la "vitrina"-espacio que difiere unos de los otros, a través de colores, formas y bienes que exhibe, como se puede transmutar en lugar de ocupación, espacio de trabajo incansable. Casa-vida, única, relacional-es locus de contradicciones.

Palabras claves: Casa. Territorialidad. Identidad. Ciudad. Pobreza Urbana. 


\section{INTRODUÇÃO}

"Uma ocasião, meu pai pintou a casa toda de alaranjado brilhante. Por muito tempo moramos numa casa, como ele mesmo dizia, constantemente amanhecendo." (Adélia Prado)

Caminhando por ruas, vielas e becos de um bairro popular, é possível que nos impressionemos com as várias formas, cores e tons que assumem as casas ali presentes. É possível, igualmente, que em razão desta diversidade apresentada, sintamo-nos curiosos em conhecer seus moradores - saber mais sobre seus amanheceres e entardeceres - curiosidade esta que, a nosso ver, só faz sentido se partirmos do pressuposto de que a casa não se configura, exclusivamente, como um "objeto", uma "edificação" - e, portanto, não é só uma estrutura arquitetônica. Ela é dotada de sentido, é significada por aquele que a habita, transmutando-se num valor.

A casa tem "voz" e "alma". Expressa um tempo, uma cultura. Reflete a dinâmica econômica, as desigualdades sociais. Diz muito da política, em sua acepção mais ampla. É território e lugar, espaço de afagos ou de dissensos. Nesse sentido, não é possível qualquer análise sobre a casa, sem que consideremos a estreita relação entre a materialidade e a imaterialidade, entre objetividade/subjetividade/intersubjetividade. Isto porque, a exemplo do que nos sugere o poeta Vallejo (1975, p.77), "as casas novas estão mais mortas que as velhas, porque seus muros são de pedra ou de aço, mas não humana. Uma casa vem ao mundo, não quando a acabam de edificar, mas quando começam a habitá-la. Uma casa vive unicamente de homens".

Através da casa, comunicamos aos outros nossa identidade; buscamos segurança e privacidade; gozamos de momentos íntimos; deixamos o "mundo" em suspenso; demarcamos nosso "pedaço"; exibimos nossas prioridades, gostos e desejos. Em seu interior, exercemos o direito à liberdade ou, ao contrário, aprisionamo-nos no mundo que construímos. Nela estabelecemos vínculos familiares, recuperamos a energia para mais um dia de trabalho ou enveredamos por uma labuta incansável. Casa - local de contradições! Enquanto espaço construído, a casa apresenta "auto consistência subjetiva" (GUATTARI, apud SAWAIA, 1995). Segundo Sawaia,

A cidade, a rua, o prédio, a porta representam modelos de subjetividade enquanto portadores de história, desejos, carências e conflitos. Cada cidade, bairro, rua, até mesmo cada casa, tem um clima que não advém, exclusivamente, do planejamento urbano e da geografia, mas do encontro de identidades em processo - identidades de homens e espaços. Esse clima perpassa diferentes entidades: eu, corpo, espaço doméstico, etnia, arquitetura. Dessa forma, os espaços construídos formam discursos e manipulam impulsos cognitivos e afetivos próprios. (1995, p.21).

Tornada sonho ou transmutada em pesadelo, a casa ocupa lugar de destaque em nossa memória, em nossos afetos e se apresenta com a promessa (por vezes ilusória) de estabilidade. Para Bachelard, 
[...] é graças à casa que um grande número de nossas lembranças estão guardadas e se a casa se complica um pouco, se tem porão e sótão, cantos e corredores, nossas lembranças têm refúgios cada vez mais bem caracterizados. Voltamos a eles durante toda a vida em nossos devaneios. (1989, p.24).

É sobre essa casa viva, relacional e, ao mesmo tempo, única que trataremos no presente artigo. E, sem dúvida, isto nos coloca como desafio a necessidade de desconstrução de quaisquer concepções sustentadas em padrões pré-concebidos, em formatos estandardizados, posto que, ainda que possamos apreender algumas regularidades nas formas assumidas por cada uma delas, dificilmente terão para seus habitantes sentidos/ significados semelhantes. Reportando-se à relação forma-conteúdo presente na arquitetura das cidades, afirma Leitão:

Que não se conclua, no entanto, ao reconhecer-se a precedência dos conteúdos sociais sobre a forma, que se minimiza o papel essencial por ela desempenhado na arquitetura da cidade. Na verdade, é ela, a forma, o meio a partir do qual os fatos urbanos se materializam e desse modo constituem o ambiente físico que se define como cidade. É por meio dela que é possível reconhecer num primeiro olhar, espaços tão diferentes quanto Paris, Bagdá ou Brasília[...] A forma, tão cara à arquitetura e aos que a ela se dedicam por ofício - e por paixão -, não surge a partir do exercício da arquitetura em si mesma, mas, antes, reflete, nela própria, acontecimentos sócio-históricos que lhe dão sustentação e, principalmente, valor simbólico. (2004, p. 25).

\section{A CASA ENQUANTO VALOR}

A casa assume junto aos segmentos populares - atores privilegiados por nós nas atividades investigativas $^{1}$ - um valor inestimável. Para a maioria deles, significa a possibilidade de integração efetiva ao bairro e à cidade e, mais que isso, elemento capaz de torná-los reconhecidos como sujeitos e autores de sua própria história. A fala de uma de nossas entrevistadas é exemplar para elucidar tal importância:

Pra mim é tudo. Porque eu nunca tive casa, essa é a primeira. Então eu batalhei muito, fiz inscrição, fiquei esperando muito pra poder obter ela... Esperei mais de dez anos. Nós somos os primeiros moradores daqui. Não tinha água, não tinha luz, não tinha calçada, não tinha nada. Era só aquela casinha, tudo escuro... E quando eu vi, eu amei ela assim mesmo. Era só uma sala, um quarto e uma cozinha pequenininha... E um banheirinho só. Não tinha muro, não tinha calçada, não tinha lâmpada na rua. Não

1 “Da 'casa-abrigo’à 'casa-bazar' - velhas e novas formas e funções dos espaços de moradia num bairro popular da Cidade do Rio de Janeiro" - é a pesquisa que desenvolvemos no bairro de Santa Cruz, situado na Zona Oeste do Rio. Partimos, para tanto, da análise de fontes documentais e bibliográficas referentes ao tema, bem como entrevistas e histórias de vida realizadas com moradores da área, além do recurso à fotografia. Com isto, procuramos compreender o valor atribuído pelos trabalhadores pobres à moradia e, sobretudo, as implicações efetivas derivadas das formas e funções assumidas pela casa, no que se refere: a) à criação/manutenção de redes familiares e comunitárias; b) à hierarquização dos padrões de consumo entre os moradores e criação de gradações/estratificações entre eles; c) à produção (posto que muitas delas se transformam em "unidades produtivas") e reprodução da força de trabalho; d) ao enfrentamento da situação de pobreza; e) ao "empreendedorismo local". Tal pesquisa teve início em 2010 e conta com o apoio do CNPq e da FAPERJ. 
tinha muro, era um passando por dentro do quintal do outro. (I, moradora do Conjunto Cesarão).

Mas não é somente para seus moradores que a casa é fundamental, ela também é de suma importância para a sociedade, dado seu papel tanto para a reprodução social do indivíduo, quanto para o consumo.

Entre os trabalhadores pobres, a construção da casa, em geral, decorre de relações permeadas, desde a aquisição do lote, pela informalidade, surgindo "à revelia dos sistemas formais de produção das moradias e das normas urbanísticas, conformando espaços de ocupação aleatória, densos, deficientes de infra-estrutura, portanto em condições de habitabilidade precária." (GORDILHO-SOUZA, 2000, p.51).

Apesar das muitas dificuldades enfrentadas pelos segmentos menos privilegiados no acesso à moradia, nenhuma, entretanto, é capaz de minimizar a importância atribuída à casa - e, aqui, leia-se casa própria - o que pode ser comprovado através de palavras ou expressões que utilizam para sintetizar tal valor: a casa "é tudo" - "abrigo", "lugar de descanso", "local de privacidade", "espaço da família”, " refúgio”, "segurança”, , propriedade", "a cara de quem mora".

Na maioria dos casos, o acesso à casa - principalmente a própria - exige de quem o vislumbra um grande e longo investimento: "Foram sete anos fazendo obra nela. Falta ainda bastante coisa... Mas ela já tem... Embaixo é toda no piso, tudo direitinho. Mas ainda falta fazer mais um quarto pra minha filha. Quando eu fui morar nela não tinha azulejo, não tinha piso", conforme nos relatou uma moradora entrevistada.

Em geral, são os próprios moradores, que assumem para si a tarefa de fazer a obra, utilizando-se de momentos que destinariam ao descanso, como os finais de semana. Além disto, toda a família e até os amigos são envolvidos neste processo e as intervenções realizadas não contemplam grande planejamento ou técnica, tampouco a contratação de engenheiros ou arquitetos, o que pode resultar em perda de material e "em moradias que apresentam defeitos de acabamento, circulação ou insolação, com baixa qualidade de conforto ambiental" (KOWARICK, 2009, p.169), tornando ainda maior o custo da construção ou, mesmo, transformando o ambiente em inadequado para uso. Cortes também costumam ser realizados no orçamento doméstico, afetando significativamente o acesso a itens básicos - como alimentação, vestuário, educação dos filhos e saúde.

Nos bairros "periféricos", a aparência inacabada de grande parte das casas reflete um processo construtivo que, em geral, se estende por décadas: "É tijolinho por tijolinho", conforme nos relatou um de nossos entrevistados. Em algumas situações, além das despesas com a construção da moradia, cada família arca paralelamente com aquelas referentes ao pagamento do lote, tendo em vista a dificuldade que os segmentos empobrecidos têm de realizar compras à vista, o que onera ainda mais o orçamento familiar.

Tão logo a família dispõe de "um teto" - um "embrião"2 capaz de abrigar seus membros - ocorre a mudança para a nova moradia. A partir daí, a realidade será

2 Por embrião, entende-se a moradia composta por três cômodos - quarto, cozinha e banheiro - que permite a sua ampliação a posteriori. 
conviver com obras por muito tempo, "comer muita poeira". Isso porque os embriões são encarados como uma situação provisória a ser mudada em razão de necessidades de ordem objetiva e subjetiva apresentadas. Assim é que, ano após ano, a casa original sofre alterações - agrega novos cômodos, cresce para os lados, para frente, para trás e para cima, tentando adequar-se ao tamanho da família, à chegada de novos membros (sejam filhos, noras, genros, netos, ou outros familiares), ou ainda para assumir uma função produtiva, constituindo-se também em espaço de trabalho. Os depoimentos abaixo ilustram bem tais considerações:

Quando eu comprei era um embriãzinho, né... Só tinha um quarto, uma salinha só... Mas aí eu fui aumentando... Aqui embaixo mesmo só tem sala, cozinha e banheiro. Aqui em cima tem os quartos... E a minha filha mora na outra rua. Meu filho que mora aqui em cima. [...] Mudei (a casa) porque a casa não cabia nada, não tinha nem como. [...] Não quero mais mudar nada. Porque... Pra mim tá bom, porque os filhos vai casando, cada um vai pro seu canto e eu não quero ficar com casa grande. Só dei uma melhoradinha porque tenho três filhos... Numa casa cubículo, só dá pra dormir um em cima do outro... Mas... Pra mim assim tá bom. (L., Conjunto Urucânia).

Antigamente tinha uma casa aqui, onde eu morava mesmo... depois essa casa nós desmanchamos, aí os herdeiros fizeram essas duas lojinhas aqui e o outro fez a padaria lá, de antigo só esse 'bazarzinho' aqui (sob a sua casa). Ela é nova, ela tem 4 anos que foi feita, eu não mexi em nada não". (Sr. J., Jesuítas).

Indubitavelmente, a função de abrigo é aquela considerada pela maioria de nossos entrevistados como a mais importante. E ela não se restringe, exclusivamente, à proteção contra as intempéries, o que seria sua função "natural". A casa abrigo, a bem da verdade, expressa o constante esforço empreendido pelos trabalhadores pobres em acolher novos membros da família e, ao mesmo tempo, otimizar recursos. Desta forma, evita-se o custo com a compra de outro terreno para a construção de uma unidade residencial em caso de constituição de nova família por parte dos filhos - o que demonstra o caráter utilitário deste tipo de iniciativa. Além disto, fica garantida a solidariedade familiar, fundamental quando o assunto é o cuidado com os idosos e as crianças, num contexto onde a realidade se apresenta desfavorável ou insuficiente no que concerne às redes de proteção social mantidas por Instituições Públicas ou pelo Terceiro Setor. A função de abrigo é primordial, outrossim, em contextos marcados pela violência, onde a população, não raramente, é tornada refém de traficantes e milicianos.

\section{SOBRE PORTAS E PORTÕES - A CONSTITUIÇÃO DE TERRITORIALIDADES}

Uma questão que merece destaque é a ausência de limites bem definidos que, em alguma medida, marca os espaços internos das casas, afetando a privacidade, sem falar 
que existe certa fluidez entre o público e o privado, o que torna a casa e a rua permeáveis uma à outra. Tais características são traduzidas por Tavares:

É importante destacar que a noção de proteção oferecida pela casa em espaços sociais desprotegidos não pode ser diretamente associada ao conceito de privacidade, uma vez que [...] a exiguidade dos espaços dificulta as especificações no ambiente interno da casa, o que se evidencia pela quase ausência de portas entre os cômodos, ou pela não subdivisão entre eles, havendo muitas vezes só o mobiliário fazendo separações. [...] Um dos fenômenos observados nesta investigação diz respeito, justamente, à permeabilidade entre os espaços públicos e privados, com intenso "escoamento" da dimensão pública para o considerado privado. Há brechas que intercalam um e outro, como por exemplo: quando os sons "vazam" de uma moradia, ou pessoas em fuga invadem as casas de outros. (2005, p.306).

Da Matta, no seu já clássico livro “A casa e a rua” (1997), também demonstra a complexidade e as ambiguidades presentes na relação entre estes dois espaços e, mais que isso, a possibilidade de uma "tornar-se" outra, em decorrência tanto de características objetivas, quanto de formas de apropriação simbólicas/territoriais:

Mas é preciso notar também que a oposição casa/rua tem aspectos complexos. É uma oposição que nada tem de estática e de absoluta. Ao contrário, é dinâmica e relativa porque, na gramaticidade dos espaços brasileiros, rua e casa se reproduzem mutuamente, posto que há espaços na rua que podem ser fechados ou apropriados por um grupo, categoria social ou pessoas, tornando-se sua "casa", ou seu "ponto". [...] Mas, assim como a rua tem espaços de moradia e/ ou de ocupação, a casa também tem seus espaços "arruados". Seja porque fazem a ponte entre o interior e o exterior - como as janelas, varandas, salas de visitas, cozinhas, entradas de serviço, dependências de empregadas e quintais -, seja porque o próprio desenho da casa tradicional urbana brasileira [...] tem um corredor de circulação que num sentido muito preciso é igual à rua como espaço único e exclusivo de relacionamento de todas as suas peças que operam como se fossem "casas". (p.55-56).

Seria igualmente ilustrativo remetermo-nos a Simmel (1996) para falarmos da associação/dissociação estabelecida pelos moradores entre a [sua] casa e a rua e, mais que isso, para compreendermos como os espaços de moradia acabam se constituindo, apesar de qualquer "permeabilidade" em relação à rua, em um "microterritório".

Simmel, no artigo intitulado "A ponte e a porta" (1996), demonstra o caráter fronteiriço assumido por esta última (a porta), assim como o fato de, através dela, também ser possível ilustrar "de maneira mais clara até que ponto separação e reaproximação nada mais são do que aspectos do mesmo ato". (p.12). Mais que isso, demonstra a possibilidade detida pelo homem de administrar o espaço, de construir perspectivas associativas/ dissociativas. Assim, postula o autor:

A porta, criando por assim dizer uma junção entre o espaço do homem e tudo o que se encontra fora dele, abole a separação entre o interior e o exterior. Como ela pode também se abrir, o fechá-la dá a impressão de um fechamento, de um isolamento 
ainda mais forte, face a todo espaço lá fora, do que a simples parede inarticulada. Esta última é muda enquanto a porta fala. Para o homem é essencial, ao mais profundo dar-se limites, mas livremente, quer dizer de maneira que possa vir a suprimir tais limites e se colocar fora deles [...] Porque o homem é o ser de ligação que deve sempre separar, e que não pode religar sem ter antes separado [...] O homem é de tal maneira um ser-fronteira que não tem fronteira. O fechamento de sua vida doméstica por meio da porta significa que ele destaca um pedaço da unidade ininterrupta do ser natural. Mas assim como a limitação informe toma figura, o nosso estado limitado encontra sentido e dignidade com o que materializa a mobilidade da porta: quer dizer com a possibilidade de quebrar esse limite a qualquer instante, para ganhar liberdade. (1996, p.12).

Por meio da porta, os moradores fecham-se em seu mundo e estabelecem um claro limite entre aqueles que são bem-vindos e os que se pretende evitar. Deixam os problemas do lado de fora ou mantêm em segredo fatos da sua intimidade. Assim, a porta possui uma dimensão multilateral, conforme aponta Maldonado (1996, p.9), comportando "a possibilidade de entrar e a possibilidade de sair", ambiguidade esta ilustrada pelos depoimentos a seguir:

Quando não to a fim de falar com ninguém, fecho tudo. (J, morador do Conjunto Urucânia)

Ah, eu sou muito família. Então, a casa é o meu porto seguro, né? Você pode sair para qualquer lugar, e você tem a casa para voltar. (J2, moradora do Conjunto Urucânia)

Interpondo limites ${ }^{3}$ entre o espaço da casa e a rua, a porta e/ou o portão costumam ser mencionados pelos nossos entrevistados como elementos fundamentais na definição do seu pedaço, conforme nos confidenciou uma moradora do Conjunto. Cabe ressaltar que este "pedaço" ou território, apesar de demarcado pelos que habitam a casa, também pode agregar vizinhos ou chegados - em suma, aqueles capazes de partilhar de determinados eventos, rituais, valores, signos e práticas identitárias - ou seja, aqueles que são bem-vindos:

Nossa casa, apesar de grande, acabava ficando pequena, porque o pai sempre gostava de casa cheia. Ele fazia da casa um albergue. Quando juntava todo mundo, a casa ficava pequena. (J, morador do Conjunto Urucânia).

Apesar de tal possibilidade, é bastante comum o discurso de que "na comunidade, é cada um com seu cada um", onde se constata uma tendência ao distanciamento entre os moradores e ao uso da casa como espaço de convivência familiar - o que não exclui conflitos entre os membros da família e mesmo a constituição de outras territorialidades no ambiente doméstico, demarcadas por outras portas e paredes que dividem o espaço interno, ou mesmo por diversas temporalidades observadas no uso dos diferentes

3 "Falar de território é fazer uma referência implícita à noção de limite que, mesmo não sendo traçado, como em geral ocorre, exprime a relação que um grupo mantém com uma porção do espaço". (RAFFESTIN, 1993, p.153). 
cômodos, o que poderia produzir "territorialidades cíclicas", conforme analisado por Souza (1995).

De qualquer modo, as territorialidades criadas expressam a consciência dos sujeitos, sua intencionalidade, forjando sua identidade e demarcando sua diferença/distinção em relação ao outro. Segundo Maffesoli, nossas representações e vivências "se enraízam, se territorializam num húmus que é fator de sociabilidade. É nesse sentido que podemos falar de 'encarnação' da sociabilidade que necessita de um solo para se enraizar". (1984, 54). Isso fica claro nos depoimentos a seguir:

Eu gosto daqui, é tranquilo. Cada um com seu cada um. Não tenho relação com bairros próximos. Eu estou sempre pronta a ajudar os vizinhos quando preciso... precisou, a gente tá aqui. Mas não gosto de estar na porta de vizinho, nem gosto de vizinho na minha. (L. Moradora do Conjunto Urucânia.

Minha casa não é um palacete, mas é limpa e arrumada. Educo meus animais. Tento não ser metida com os vizinhos, mas não deixo todo mundo entrar. É você saber conviver com seus vizinhos. Eu tenho que respeitar seus limites e eles os meus. Mas eu me dou bem com todos. (Z, Moradora do Conjunto Urucânia)

\section{4 "É CASA DE POBRE, MAS É AJEITADINHA" - A CASA-VITRINE ENQUANTO ELEMENTO DE DISTINÇÃO SOCIAL}

Além do papel exercido pela porta na demarcação de territorialidade, há outros elementos que, em contextos marcados pela pobreza, assumem papel crucial no estabelecimento de distâncias, hierarquias e distinção entre os moradores, embora eles nem sempre admitam tal fato sem constrangimentos: a estética da casa, da mesma maneira que o mobiliário e os equipamentos que congrega costumam deter tal funcionalidade. A casa, transmutada em vitrine, reflete o esforço de seus moradores em demonstrar que progrediram, que melhoraram de situação e isso pode, em alguma medida, despertar sentimentos de inveja e despeito entre os vizinhos. Os depoimentos abaixo são bem ilustrativos neste sentido:

Lugar pequeno, minha filha. Se você compra um carrinho, se você melhora um pouquinho, sabe como é que são as pessoas, né? Isso aí eu acho que é geral. Ainda mais comunidade assim... De lugar muito pequeno... Tem pessoas que tem a mente muito pequena. Aí tem os olhares... Às vezes até comentários. Tem pessoas que por não conseguir progredir fica desejando o dos outros... (S, Moradora do Conjunto Urucânia)

Tem alguns que fazem a melhoria e se acham melhores do que aquele que naquele momento não pode fazer. Então minha família, a gente tá fazendo aos poucos, a minha casa tá do jeito que tá mas foi feito aos poucos, e nem por isso eu menosprezo a minha vizinha que não tem condições de fazer. A casa dela é horrível, é como um dia a minha foi... No tijolo. Então eu não menosprezo por a casa dela ser assim, mas tem gente que menospreza. Na mesma rua, por exemplo... A minha casa é melhor do que a dela... Tem piso, azulejo, tem toda a comodidade... A gente tá trabalhando pra 
melhoria mesmo. Então, a minha filha brinca com a filha da vizinha... Mas o vizinho da frente não deixa as filhas dele brincar com as filhas dela. Porque ela é mais humilde, as filhas dele não podem brincar com as filhas dela. (S2, Moradora do Conjunto Urucânia)

Às vezes, tem gente que não pode ver você trocar de carro, melhorar a casa. Não vê que tem sacrifício nisso tudo. São as pessoas de "olho grande". Eu fico doente quando alguém pergunta se quero vender meu carro. Tem os ambiciosos que correm atrás, mas tem também os que ficam "malhando". (C, morador do Conjunto Urucânia)

Por causa das melhorias que empreendem na casa, bem como dos bens que adquirem, os moradores acreditam ser possível o afastamento dos estigmas que envolvem a pobreza em associação aos espaços de moradia, em especial a favela. É como se esta - a favela - fosse passível de ser incorporada pelos sujeitos sociais como um "modo de vida" capaz de deixar marcas indeléveis principalmente naqueles que nela residem ou naqueles que, em algum momento da vida, por ela passaram - a exemplo do que ocorre com alguns moradores de conjuntos habitacionais. Estas "marcas", de modo geral, tanto podem decorrer da associação direta entre pobreza/favela/violência, quanto podem referir-se à desorganização, sujeira - características que, historicamente, também foram impingidas aos espaços de moradias populares (como cortiços e favelas). Essas duas acepções marcam o depoimento de uma moradora do conjunto habitacional onde realizamos parte de nosso trabalho empírico:

Se bem que tem pessoas agora que vieram de comunidade. Aqui nós somos uma comunidade carente, mas uma comunidade que tem uma renda mais baixa que a nossa tem uma índole assim muito ruim, entendeu? De tipo... de roubo, de briga, entendeu? De baderna mesmo. Eu gosto do bairro sim, não tenho nada que reclamar não... nunca fui roubada, me dou bem com todos os meus vizinhos próximo da minha casa e longe da minha casa. É, como se diz, eu faço parte da boa vizinhança, entendeu? [...]

Se você tem uma casa melhorada seus vizinhos te tratam de uma maneira; se a sua casa é abaixo da renda seus vizinhos também te tratam bem, mas se você for uma pessoa porca, que deixa o quintal mal cheiroso, bichos mal cheirosos, roupa suja pendurada, infelizmente você é mal visto, tem certo tipo de preconceito. (J, 40 anos)

Tornada "vitrine", a casa também pode permitir aos segmentos populares a experiência de saída de uma "condição periférica" e, em alguma medida, facilitar sua entrada num "circuito globalizado". Neste sentido, alguns bens e serviços colocam-se como fundamentais, como as antenas parabólicas e os serviços de internet e tv por assinatura (ou o "gatonet" ${ }^{4}$ ).

Para as famílias, costuma ser motivo de alegria o momento de chegada da nova mercadoria, que geralmente assume um lugar de destaque na casa, passível de ser vista

4 Gatonet - designação atribuída à captura clandestina de sinal de tv a cabo ou telefonia, prática bastante usual em alguns bairros populares. Em geral, tais "serviços" são oferecidos ou impingidos aos moradores pelos traficantes ou milicianos, por valores abaixo daqueles cobrados pelas concessionárias ou empresas responsáveis por serviços de comunicação. 
pelos vizinhos. São também bastante frequentes as festas e churrascos para a inauguração do terraço ou da piscina, da mesma maneira que é usual o convite feito aos amigos para conhecerem a mobília nova, os novos cômodos, ou para assistirem ao futebol na "tv de tela grande".

Eu fui convidada para ir hoje a um churrasco na casa de I.. Ela está toda prosa, porque vai inaugurar a casa depois da reforma... tem até terraço. Vai ser boca livre. (Moradora de um loteamento)

O fato de morarem numa área marcada pela precariedade e por pouca "visibilidade" no contexto citadino faz com que prevaleça entre os moradores certo ceticismo em relação às possíveis melhorias, a investimentos em infraestrutura urbana e demais serviços por parte do Estado. Assim, formula-se um "conceito" de viver bem que não abarca o acesso aos serviços ou aos equipamentos de consumo coletivo. Ao contrário, refere-se à busca e ao usufruto de bens que lhes permitam certo distanciamento de toda uma pecha que envolve o "morar num conjunto" (pobreza, origem favelada, falta de infraestrutura etc) e uma tentativa de aproximação aos padrões de consumo de grupos hierarquicamente superiores, grupos estes que, em busca da distinção, ver-se-ão "obrigados a investir em novos bens a fim de restabelecer a distância social original" (FEATHERSTONE, 1995, p.85). Para compreendermos ainda melhor tal processo, poderíamos nos reportar a Bourdieu, que afirma:

Os gostos obedecem, assim, a uma espécie de lei de Engels generalizada: a cada nível de distribuição, o que é raro e constitui um luxo inacessível ou uma fantasia absurda para os ocupantes do nível anterior ou inferior, torna-se banal e comum, e se encontra relegado à ordem do necessário, do evidente, pelo aparecimento de novos consumos, mais raros e, portanto, mais distintivos. (1983, p.85).

Baudrillard, referindo-se aos imperativos do consumo, sugere que assim como "a concentração industrial origina o aumento constante de bens, também a concentração urbana suscita a eclosão ilimitada das necessidades". (1995, p.65). O consumo, observado sob tal ótica, teria um caráter ilimitado, onde os objetos, as mercadorias não são consumidos pelo seu valor em si (seu valor de uso), mas como signos, símbolos de distinção, como "comunicadores". (p.60). A preferência por determinados bens ou a realização de determinadas escolhas funcionam como demarcadores de classe e, mais que isso, os estilos de vida soam como "a retradução simbólica de diferenças". A fala a seguir expressa tais reflexões:

Eu gosto da minha casa sempre bem arrumada, com os móveis direitinhos, bem equipadinha. Não é porque moro em conjunto que vou deixar de viver bem, não é mesmo? Estou juntando dinheiro para comprar um computador para as crianças, e logo depois quero comprar uma tv de plasma. Tô só esperando baixar o preço. É sempre assim, as coisas são caras no começo, mas depois o preço cai. (Moradora do conjunto Guandu, em Santa Cruz). 
Como pudemos constatar nesse depoimento, existe uma preocupação quanto ao acompanhamento das novidades do mercado, demonstrando uma busca pela adequação a uma sociedade pautada, como nos diria Bauman, num "tempo pontilhista composto de instantes", onde a mensagem transmitida "oferece o bônus duplo de deixar o consumidor momentaneamente atualizado e ao mesmo tempo portando uma salvaguarda que evite ficar para trás no futuro [...] Consumidores experientes vão captar a mensagem, que os estimulará a se apressarem e os lembrará que não há tempo a perder." (2008b, p.109).

Esta “consciência" acerca da obsolescência dos produtos e a constante preocupação em estar à frente, em demonstrar sucesso e sentirem-se pertencentes a um padrão de vida que consideram como referente a um grupo ou classe hierarquicamente superior no caso a classe média - pode levar os trabalhadores pobres ao endividamento, ao abuso dos crediários, à permanência no "vermelho".

Pelo que temos podido constatar, tanto através das observações realizadas no bairro, como por meio das entrevistas, as reformas e melhorias empreendidas nas casas atenderiam, em suma, a quatro pressupostos fundamentais (MAIA, 2011):

a. De ordem estética: os moradores concentram seus esforços no sentido de tornar suas casas "mais bonitas", "mais vistosas". Para tanto, há uma preocupação quanto à escolha do material (tinta, tipo de telhado, piso etc) a ser usado na construção ou reforma. Em geral, acompanham as tendências do mercado, muitas vezes "orientados" pela mídia - novelas e programas de entretenimento costumam funcionar como "termômetros".

b. De ordem funcional: atender às necessidades objetivas dos moradores - não somente em relação aos cômodos/áreas internas, bens de consumo duráveis - que precisam estar adequados às necessidades objetivas da família, mas também àqueles espaços voltados à sociabilidade e ao lazer, que permitem a convivência vicinal.

Assim, é comum observarmos, em muitas casas situadas nos bairros periféricos, a presença de terraço, churrasqueira, piscina (ainda que de plástico), que funcionam como elementos agregadores da família e dos vizinhos mais próximos. Em torno deles, juntam-se para assistir ao futebol, fazem o churrasco, ouvem o pagode. Num contexto onde os equipamentos culturais e de lazer são precários, ou inexistentes, tais espaços de convivência costumam ser valorizados, assumindo papel crucial, inclusive, na instituição de territorialidades.

c. De ordem relacional: destacar-se em relação às demais moradias. Tal fato já foi mencionado em outro momento do texto e costuma aprofundar o distanciamento social, contribuindo para a criação de hierarquias entre os moradores e, em alguma medida, inviabilizando o empreendimento de ações/lutas que tenham em vista a resolução de questões coletivas - característica esta que não é prerrogativa das classes populares.

Nesse sentido, foram muitos os depoimentos que deixaram claro que, com as melhorias que fazem nas casas, alguns moradores, sobretudo aqueles que vêm de áreas mais "nobres" da Cidade, buscam demarcar um lugar diferenciado no bairro $e$ "já chegam construindo casarões", como nos disse uma das entrevistadas. E ela própria continuou: "Aí, não tem outro jeito: fica cada um com o seu cada um", deixando claro a prevalência de posturas individualistas. 
Além destes "outsiders", recém-chegados, há indícios de que alguns dos casarões existentes na localidade tenham como proprietários os ditos milicianos. Não há uma referência explícita a isso no depoimento dos moradores - talvez por receio, medo. Pelas casas e pelo esquema de segurança que muitas delas detêm, o desejo destes atores talvez seja o de comunicar "que são os donos do lugar".

d. Segurança - obsessão que também começa a ganhar força entre os segmentos populares: muros, porteiros eletrônicos, câmeras fazem parte do contexto de muitas casas e podem tanto promover a distinção entre os moradores, quanto aprofundar o distanciamento entre eles. O medo aparece como o fantasma a rondar as suas vidas e o mal coloca-se como algo iminente.

As análises de Bauman (2008a) são fundamentais à elucidação de tal fenômeno. Segundo o autor, na contemporaneidade - ou, como prefere, na "modernidade líquida" - não há mais sinais ou fronteiras claramente definidos que nos tornem aptos a identificar ou separar o bem do mal, identificar amigos e inimigos. O mal se apresenta a partir de qualquer lugar, a qualquer momento. Por isso vivemos num momento de crise de confiança, o que ameaça as relações humanas e os vínculos sociais e torna a cidade fonte de perigo constante. Assim, os moradores passam a depositar na tecnologia a esperança de uma vida melhor e mais segura.

Entretanto, há que se considerar que o medo - na realidade, inadministrável e indefensável - também é distribuído desigualmente, independendo de sua causa específica. Assim, a segurança, o conforto e mesmo a felicidade tornam-se privilégios de poucos, contribuindo para a ampliação da desigualdade social (BAUMAN, 2008a).

\section{CONSIDERAÇÕES FINAIS}

A análise acerca da casa aqui realizada nos permite afirmar, neste momento, que não há como compreendermos a dinâmica de qualquer "lugar" e o protagonismo de seus moradores com um olhar que contemple dimensões exclusivamente materiais/objetivas, ou que priorize o papel assumido por governantes, empresários e demais atores no que se refere à produção do espaço. Tais dimensões não são, em si, capazes de "descortinar" as distintas apropriações simbólico-culturais evidenciadas; tampouco os indicadores socioeconômicos e políticos são suficientes para permitir uma análise acerca das territorialidades, das hierarquias e das práticas estigmatizantes que marcam as relações estabelecidas pelos moradores, que não raro, desembocam em situações de discriminação, abalam a sociabilidade, as experiências associativas, a confiança e a mobilidade, trazendo implicações na construção da identidade de indivíduos e grupos sociais, tornando-os ainda mais vulneráveis.

Por outro lado, temos clareza de que o fortalecimento destes moradores e a assunção da condição de sujeitos-citadinos também implica a busca de respostas a algumas indagações capazes de avaliar não somente o sentido, mas também a legitimidade e a funcionalidade dos diversos usos e apropriações experimentados por eles na produção/ 
apropriação da casa: a) Seriam estratégias legítimas de enfrentamento da pobreza num contexto de "carência" de políticas sociais? b) Permitiriam a emergência de uma postura crítica frente a tal carência, viabilizando a implementação de ações coletivas e de luta pela conquista/ampliação dos direitos sociais? c) Seriam, ao contrário, passíveis de repressão por parte do Estado, pelo fato de basearem-se, em muitos casos, em situações marcadas pela informalidade/ilegalidade? Cremos que respostas a tais questionamentos poderão contribuir para se pensar em políticas públicas (de habitação, geração de emprego e renda, dentre outras), adequadas às demandas efetivas de uma população que se depara, cotidianamente, com uma realidade que não só lhe é desfavorável no que se refere ao acesso a bens e serviços, mas que (re)produz estereótipos, forja estigmas territoriais e, em grande medida, cria restrições quanto ao direito à cidade.

\section{REFERÊNCIAS}

BACHELARD, Gaston. A poética do espaço. São Paulo: Martins Fontes, 1989.

BAUDRILLARD, Jean. A sociedade de consumo. Lisboa: Edições 70, 1995.

BAUMAN, Zygmunt. Medo líquido. Rio de Janeiro: Zahar, 2008a.

Vida para o consumo: a transformação das pessoas em mercadoria. Rio de Janeiro: Jorge Zahar Editor, 2008b.

BOURDIEU, Pierre. Sociologia. São Paulo: Ática, 1983.

DA MATTA, Roberto. A casa \& a rua: espaço, cidadania, mulher e morte no Brasil. 5 ed., Rio de Janeiro: 1997. Disponível em: <http:/ / www.taddei.eco.ufrj.br/AntCom/DaMatta_1997_ACasaeaRua.pdf> Acesso em: 20 fev. 2012.

FEATHERSTONE, M. Cultura de consumo e pós-modernismo. São Paulo:

Studio Nobel, 1995.

GORDILHO-SOUZA, Ângela. Limites do habitar: segregação e exclusão na configuração urbana contemporânea de Salvador e perspectivas no final do século XX. Salvador: EDUFBA, 2000.

KOWARICK, Lúcio. Viver em risco: sobre a vulnerabilidade socioeconômica e civil. São Paulo: Editora 34, 2009.

LEITÃO, Lúcia. Espelho, espelho meu. Cadernos de Arquitetura e Urbanismo, Belo Horizonte, v. 11, n. 12, p. 13-32, dez. 2004.

MAIA, Rosemere. Os tons da periferia: notas sobre pobreza, segregação e hierarquias. In: REUNIÃO DE ANTROPOLOGIA DO MERCOSUL, 9. Curitiba, 2011. Anais... Disponível em: <http://www.ram2011. org/> Acesso em: 02 jan. 2012.

MAFFESOLI, Michel. A conquista do presente. Rio de janeiro: Rocco, 1984.

MALDONADO, Simone. Georg Simmel: uma apresentação. Política e Trabalho, n. 12, p. 05-09, set. 1996.

RAFFESTIN, Claude. Por uma geografia do poder. Rio de Janeiro: Zahar, 1993.

SAWAIA, Bader B. O calor do lugar: segregação urbana e identidade. Revista São Paulo em Perspectiva. v. 9, n. 2, p. 20-24, abr.-Jun., 1995.

SIMELL, Georg. A ponte e a porta. Política e Trabalho. n. 12, p. 10-14, set. 1996. Disponível em: <http:/ / reocities.com/CollegePark/library/8429/12-simmel-1.html> Acesso em: 25 fev. 2012.

SOUZA, Marcelo J. L. O Território: sobre espaço e poder, autonomia e desenvolvimento. 
In: CASTRO, Iná E.; GOMES, Paulo C.C. e CORRÊA, Roberto L. (orgs.). Geografia: conceitos e temas. Rio de Janeiro: Bertrand Brasil, 1995.

TAVARES, Sandra Maria Greger. Moradia e corporeidade em espaços liminares: um estudo sobre formas de subjetividade na favela. Paidéia, v. 15, n. 31, p. 299- 308, 2005.

VALLEJO, César. Obra poética completa. Casa de las Américas. 3 ed. 1975.

Recebido em 23/01/2012

Aceito para publicação em 08/04/2012 